Brit. J. industr. Med., 1950, 7, 70.

\title{
BERYLLIUM GRANULOMATA IN THE LUNGS OF RATS
}

BY

\author{
T. A. LLOYD DAVIES and H. E. HARDING \\ From the Industrial Health Unit, Boots Pure Drug Co. Ltd., Nottingham, \\ and the Department of Pathology, the University of Sheffield
}

(RECEIVED FOR PUBLICATION DECEMBER 19, 1949)

At the Ninth International Congress on Industrial Medicine Policard (1948) reported the production of granulomata in the lungs of rats and guinea-pigs by dusting with beryllium oxide. Details of the particle size of the dust were not given. Policard claimed that hyperplasia of the mesenchymatous cells of the lung after dusting with beryllium oxide resulted in three types of response (1) histiocytic pneumonia, (2) granulomatous nodules, mainly in guinea-pigs, and (3) cellular thickening of the alveolar walls, particularly in rats.

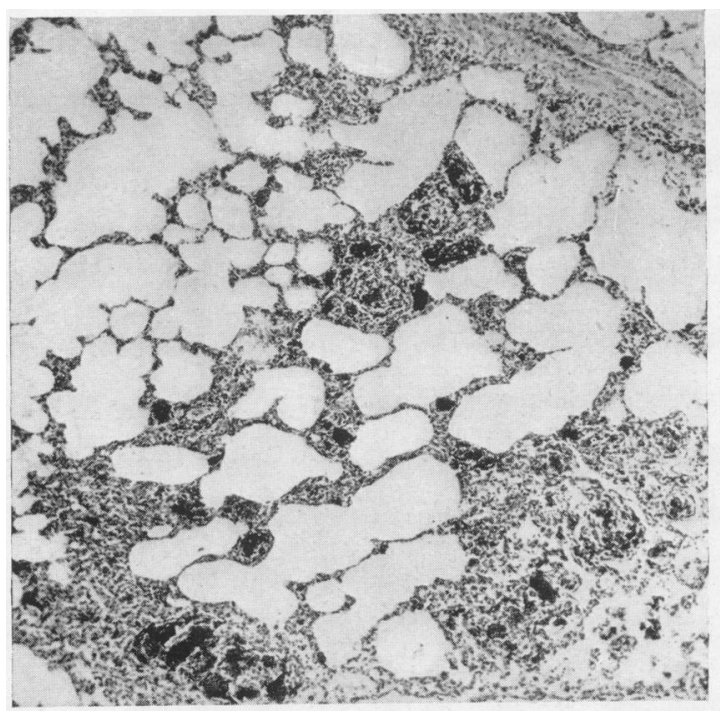

FIG. 1.-Four weeks after intratracheal injection of beryllium oxide suspension in skimmed milk (Rat No. 230). There are multiple granulomatous follicles around a persistent aggregate of dust. The resemblance to illustrations in the paper by De Nardi and others (1949), reporting 10 human cases of chronic pulmonary granulomatosis, should be noted. $(\times 50$. $)$

\section{Method}

Using the method we have previously described (Lloyd Davies and Harding, 1949), we have introduced amorphous beryllium oxide into the lungs of 23 rats by the intratracheal injection of $50 \mathrm{mgm}$. beryllium oxide (75\% of particles less than one micron in size) in $1 \mathrm{ml}$. of normal saline ( $p \mathrm{H}$ of suspension $6 \cdot 8$ ) or of skimmed milk ( $p \mathrm{H}$ of suspension $8 \cdot 0$ ). The resultant histological changes are inconstant, but multiple small granulomata of foreign body type composed of small mononuclear cells (lymphocytes and histiocytes) with an occasional multinuclear cell and infiltration of the surrounding interstitial tissues by similar cells commonly result (Figs. 1, 2, and 3). The introduction by intratracheal injection of any dust, for example, zircon, manganese dioxide, silica, or graphite into the lung, if in sufficient quantity and of the right particle size, may lead to foreign body granulomata as a normal or physiological reaction (Fig. 6). Occasionally, larger and different granulomata appear after the intratracheal injection of beryllium oxide, especially when some further stimulus to histiocytic proliferation is present. Eleven additional rats were injected with a mixture of $50 \mathrm{mg}$. each of beryllium oxide and manganese dioxide in sterile sus-

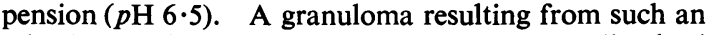
injection is illustrated in Figs. 4 and 5 . Undissolved particles of beryllium oxide, readily distinguished under the microscope by the yellow colour of the particles, are

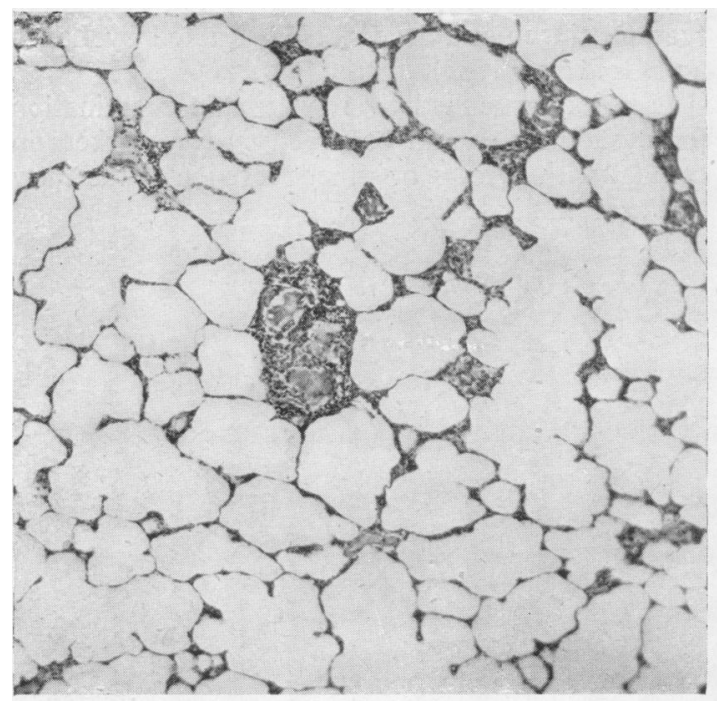

FIG. 2.-Four weeks after injection of beryllium oxide and manganese dioxide suspension in normal saline (Rat No. 484). Similar appearance to that in Fig. 1. $(\times 50$. 


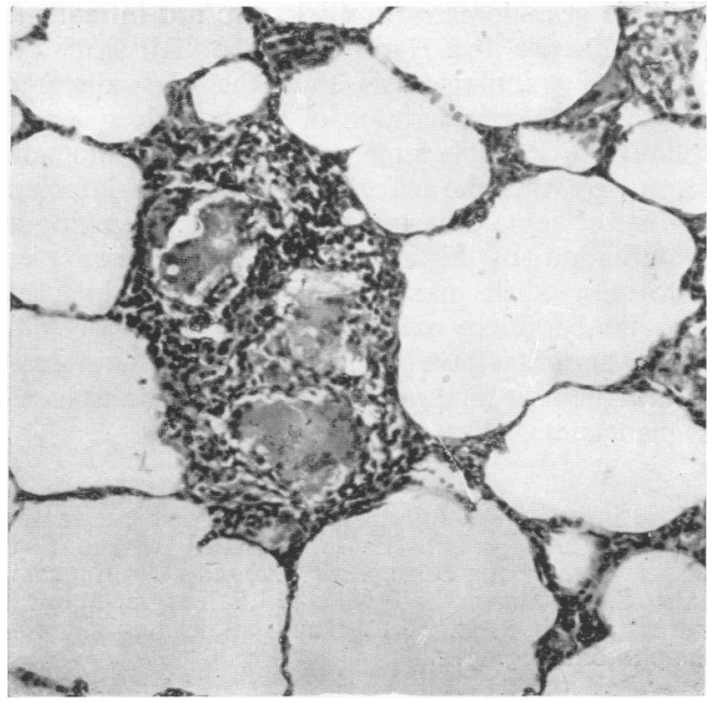

Fig. 3

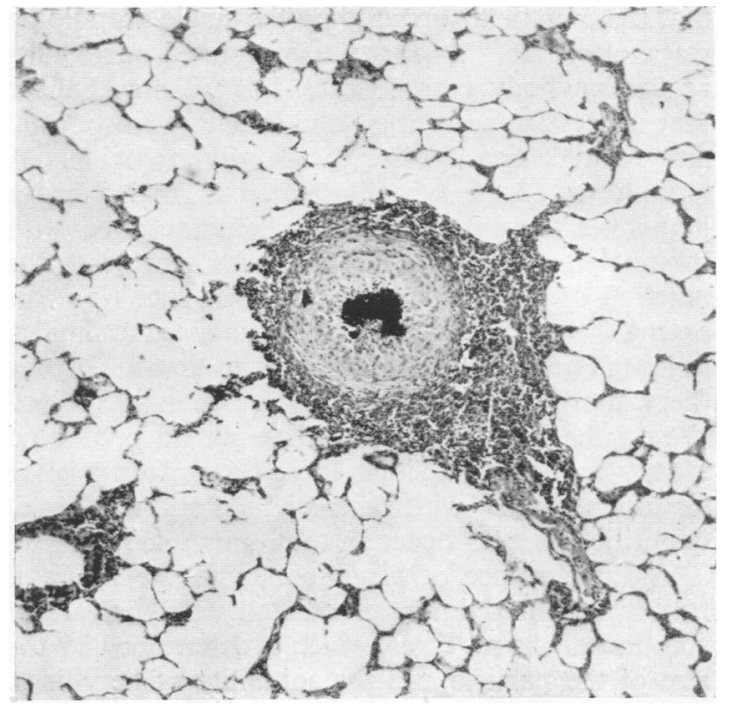

FIG. 4

Fig. 3.-Enlargement from Fig. 2. Granulomatous follicle with giant cells. $(\times 150$.$) Fig. 4.-Twelve weeks$ after intratracheal injection of beryllium oxide and manganese dioxide suspension in normal saline (Rat No. 489) showing cellular formation of granuloma around persistent aggregate of beryllium oxide dust. $(\times 50$.)

seen in the centre of a collection of large histiocytes surrounded by a broad zone of small histiocytes and lymphocytes that infiltrate into the surrounding lung tissue. We were led to use such a mixture partly because our previous experience with manganese dioxide had shown that it evoked a response that was characteristically histiocytic, and partly because fluorescent powders used

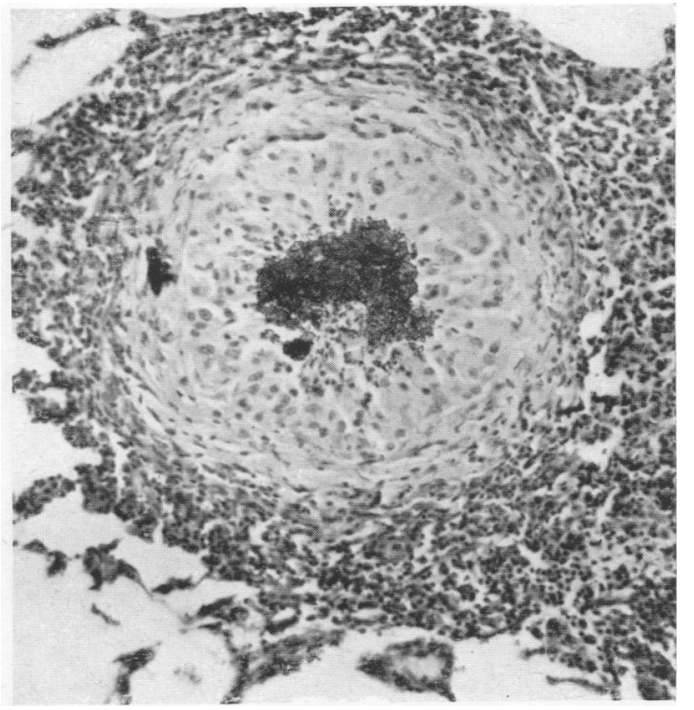

FIG. 5 in the manufacture of strip lamps are known to contain manganese.

\section{Discussion}

Policard has not made further reports of his observations; his microhistological slides were unsatisfactory since the magnification was so great

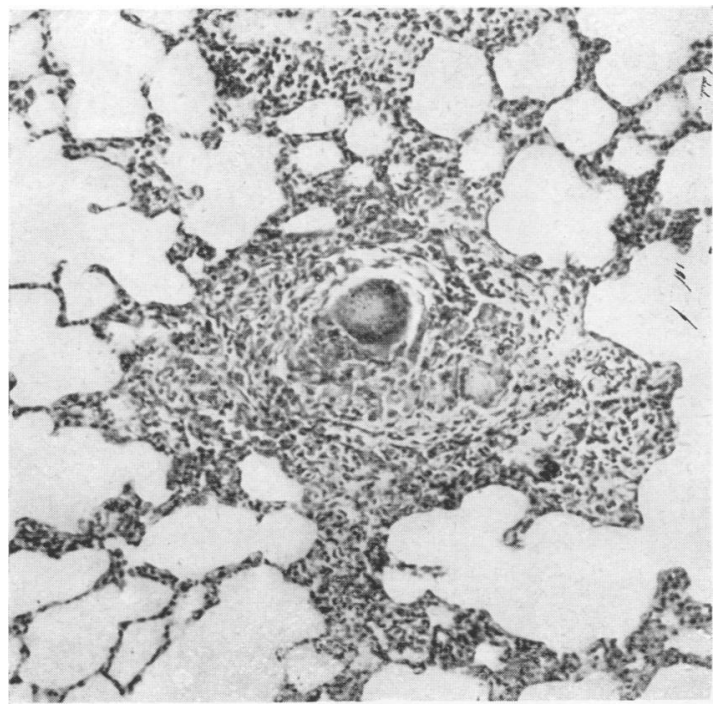

Fig. 6

Fig. 5.-Enlargement from Fig. 4 showing cellular formation of granuloma. $(\times 150$. $)$ Fig. 6.-Four weeks after intratracheal injection of zircon suspension in normal saline (Rat No. 214) showing cellular formation of granuloma ; note difference from Fig. 5. Apart from the presence of crystals this was the sole abnormality found in the lungs of this animal. $(\times 150$.) 
that the lung field surrounding the single granuloma was not visible. At first we interpreted our results as foreign body granulomata, but we now believe that at least some of the granulomata we produced are related specifically to beryllium oxide. A granuloma of the type illustrated in Fig. 5 has a highly cellular character, and when associated with infiltration of the interstitial tissues represents the reaction of the lung to chronic irritation. To this extent the reaction we produced may be a similar, although limited, type of reaction to that in chronic (beryllium) granulomatosis in the human subject. We emphasize that the technique we have adopted is very artificial; a single large dose of dust is far from comparable with repeated inhalations of small quantities such as occur in the human subject.

The occurrence of granulomata in the lungs of rats is, in our opinion, associated with the rate of solution of the particles, which is determined by the size of the particle and the solubility of beryllium. Reactions such as granulomata, which are of a chronic nature, occur when particulate dust persists in aggregations to form a continuing irritant focus. Beryllium oxide is relatively insoluble and disappears slowly from the lung. In the case of manganese its greater solubility does not allow of the formation of large granulomata, although small multiple granulomatous follicles are not infrequent (Lloyd Davies and Harding, 1949). All work on beryllium granulomatosis and other dust diseases must include consideration of the particle size and solubility. Possibly large, well-formed granulomata result only when the action of beryllium is reinforced by that of some other agent or agents provoking a proliferation of histiocytes. Our best examples were seen when manganese dioxide was injected with the beryllium oxide. Most, and possibly all, of the dusts that have produced chronic granulomatosis in man are mixtures containing such substances as manganese, silica and zinc.

The intratracheal injections were carried out in the Research Department (Pharmacological Division) of Boots Pure Drug Company Limited, Nottingham. Miss E. Wilkinson and Miss E. Parker gave much technical help. Mr. T. C. Dodds of Edinburgh took the photomicrographs.

\section{REFERENCES}

De Nardi, J. M., Van Ordstrand, H. S., and Carmody, M. G. (1949). Amer. J. Med., 7, 345.

Hardy, Harriet L., and Tabershaw, I. R. (1946). J. industr. Hyg., 28, 197.

Lloyd Davies, T. A., and Harding, H. E. (1949). British Journal of Industrial Medicine, 6, 82 .

Policard, A. (1948). Proceedings of Ninth International Congress of Industrial Medicine, London, p. 796. 